BMJ Open Sport \& Exercise Medicine

\title{
Indicators and correlates of low energy availability in male and female dancers
}

Nicola Keay (D) , ${ }^{1}$ AusDancers Overseas, ${ }^{2}$ Gavin Francis $^{3}$

To cite: Keay N, Overseas A, Francis G. Indicators and correlates of low energy availability in male and female dancers. BMJ Open Sport \& Exercise Medicine 2020;6:e000906. doi:10.1136/ bmjsem-2020-000906

- Additional material is published online only. To view please visit the journal online (http://dx.doi.org/10.1136/ bmjsem-2020-000906).

Accepted 10 November 2020

\begin{abstract}
Objectives To investigate indicators and correlates of low energy availability (LEA) in male and female dancers. Methods A Dance-Specific Energy Availability Questionnaire (DEAQ) was developed and administered online internationally to dancers training at preprofessional, professional or advanced amateur level. The DEAQ drew on current validated, published questionnaires for LEA, linked to the clinical outcomes of relative energy deficiency in sport (RED-S). Questions addressed recognised physiological indicators and consequences of LEA in the context of dance, together with potential correlates. LEA was quantified using a scoring system to include these characteristics.
\end{abstract}

Results 247 responses to the DEAQ were analysed (225 female and 22 male), mean age 20.7 years (SD 7.9) with $85 \%$ practising ballet. Psychological, physiological and physical characteristics consistent with LEA were reported by $57 \%$ of the female dancers and $29 \%$ of male dancers, indicating a risk of RED-S. The unique nature of dance training, in terms of demands and environment, was found to be potentially influential in development of this situation. Less than one-third (29\%) of dancers were aware of RED-S.

Conclusion This study found dancers to be a specific group of high-level artistic performers displaying indicators of LEA and consequently at risk of developing the adverse clinical health and performance consequences of RED-S. Awareness of RED-S was low. The DEAQ has the potential to raise awareness and be a practical, objective screening tool to identify dancers in LEA, at risk of developing RED-S.

Check for updates

(c) Author(s) (or their employer(s)) 2020. Re-use permitted under CC BY-NC. No commercial re-use. See rights and permissions. Published by BMJ.

${ }^{1}$ Department of Sport and Exercise Sciences, Durham University, Durham, UK ${ }^{2}$ AusDancersOverseas, Merzhausen, Germany ${ }^{3}$ Science4Performance, London, UK

Correspondence to Dr Nicola Keay; nickykeayfrancis@googlemail. com

\section{INTRODUCTION}

The effects of low energy availability (LEA) disrupting physiological function in the short term and long term were initially described in female dancers. ${ }^{1-4}$ However, subsequently, the focus has been on athletes in sport resulting in the International Olympic Committee (IOC) consensus statement on relative energy deficiency in sport (RED-S). ${ }^{5}$ RED-S describes the adverse health and performance outcomes caused by LEA. ${ }^{6}$ RED-S is prevalent in sports where low body weight confers a performance or aesthetic advantage. ${ }^{6}$

While there are direct parallels between the demands of training and performance, a cultural divide separates dance and sport. This is reflected at the organisational level,

\section{What are the new findings?}

- Dancers reported many recognised indicators of low energy availability (LEA) and consequently are at risk of developing the adverse health and performance outcomes of relative energy deficiency in sport (RED-S).

- Few dancers in this study demonstrated an awareness of RED-S.

- The nature of dance training, in terms of demands and environment, was found to be potential determinants of the development of LEA in dancers.

- The Dance-Specific Energy Availability Questionnaire (DEAQ) is the first questionnaire specific to dancers. Applying a scoring system to the responses from the $D E A Q$ can provide an objective assessment of LEA.

How might this study impact on clinical practice in the future?

- As low energy availability (LEA) and subsequent risk of relative energy deficiency in sport (RED-S) is not matched by awareness, providing educational resources for the dance community is important. $A$ British Association of Sport and Exercise Medicine website has been developed by the research team for both athletes and dancers, www.health4performance.co.uk.

- The Dance-Specific Energy Availability Questionnaire has the potential to be a practical, objective, healthscreening tool and to identify male and female dancers worldwide in LEA. By identifying these dancers, support could be targeted to modify dancer behaviours to reduce the risk of dancers developing the adverse health and performance sequelae of RED-S.

- Early identification of dancers at risk of developing RED-S is of particular importance when situations arise out of dancers' control, such studios and theatres closing in pandemics or time off dancing due to illness/injury. Targeted support may be required as a dancer's tendencies towards exercise dependence and disordered eating patterns may increase as a way to seek control and combat uncertainty.

where the governing bodies of sport and dance are separate. This study has the dual aims of bridging this divide, in order to bring to the dance community the benefit 
of advances made in sport, and of shedding light on the indicators and correlates of LEA.

Previous studies have avoided the pitfalls of direct measurement of energy availability (EA) ${ }^{7}$ by adopting a questionnaire approach to identify physiological indicators of LEA; but these studies have tended to focus on endurance sports. ${ }^{8}$ For example, a validated questionnaire exists for the female athlete triad: the Low Energy Availability in Females Questionnaire: LEAF-Q. ${ }^{9}$ LEA in female athletes measured using a self-reported questionnaire is strongly associated with many health and performance consequences of RED-S. ${ }^{10}$ In male athletes, a self-reported questionnaire found evidence of exercise hypogonadal condition and other physiological indicators of RED-S. ${ }^{11}$ A Sport-Specific Energy Availability Questionnaire combined with Interview (SEAQ-I) ${ }^{12}$ for male cyclists was effective in indicating low bone mineral density (BMD) of the lumbar spine, characteristic of RED-S. The IOC RED-S Clinical Assessment Tool (RED-S CAT) ${ }^{13}$ is applicable to male and female athletes, but is designed for medical professional use only.

Combining these approaches and tailoring for the dance community would be of great clinical value for dancers potentially at risk of developing the adverse outcomes of LEA.

The objectives of this study were to investigate indicators and potential correlates of LEA in male and female dancers.

\section{METHODS}

\section{Study design}

A cross-sectional, observational study of a newly developed questionnaire was designed to assess the risk of RED-S in male and female dancers. The study was approved by the Durham University ethics committee. Participants provided informed consent before completing the online, anonymous questionnaire.

\section{Recruitment}

Participants were recruited to the study through contacts of the researchers with dancers and dance organisations via email inviting completion of an online questionnaire, which was open from April 2019 to April 2020. Dancers were eligible to take part in the study if training at preprofessional, professional or advanced amateur level.

\section{Dance-Specific Energy Availability Questionnaire}

The Dance-Specific Energy Availability Questionnaire (DEAQ) drew on validated questionnaires for athletes in sports, including LEAF-Q ${ }^{9}$ SEAQ-I,${ }^{12}$ RED-S CAT ${ }^{13}$ and androgen deficiency. ${ }^{14}$ Dancer descriptive characteristics included age and self-reported body weight and height. Questions covering training, attitudes to weight and eating behaviours were tailored to be dance specific. The presentation and order of questions were considered to ensure engagement from dancers. The questionnaire was reviewed by the Sports Sciences Department at Durham University, including a psychologist and dance medicine endocrinologist, and by medical and nutritional professionals at AusDancers Overseas and dancers for content validity.

The DEAQ (online supplemental file 1) was administered online using the Jisc survey tool.

A RED-S Risk Score was formulated, applying a points system to DEAQ responses particularly indicative of LEA in line with, and expanding on, current validated questionnaires for athletes in sport, as shown in online supplemental file 2. Relevant indicators included physical factors, such as body mass index (BMI), lowest weight, injuries; physiological factors, including indicators of sex steroid hormone levels, gut issues; psychological aspects including dietary and exercise behaviours, measures of well-being (freshness, sleep), attitudes to controlling exercise, diet and weight and any history of a diagnosed eating disorder.

\section{Statistical analysis}

Data analysis was performed using the open source tools, SciPy and Pandas (NumFOCUS, Austin, Texas), implemented using the Python programming language. Summary statistics, including count, mean and SD of responses, were calculated for the overall sample and by subgroup, according to the responses to the questions. A two-sample t-test was applied to identify differences between the means of subgroups, using a $5 \%$ significance level.

BMI was calculated by dividing weight $(\mathrm{kg})$ by the square of height $(\mathrm{m})$. Minimum BMI (BMI min) was calculated based on the dancer's minimum weight for current height. A weight variability variable was calculated for the current height by dividing the difference between the maximum and minimum weights by the current weight.

\section{Public involvement}

Public involvement was integral at all stages of this research. The conception of an objective survey arose from discussions with dancers. While the questions were based on validated questionnaires, dancers contributed to drafting questions in the context of dance training and suggesting extra dance-specific questions. Anonymisation of responses was agreed. Dancer networks supported recruitment and will support dissemination of the findings with independent dance organisations, dance publications and international dance meetings.

\section{RESULTS}

\section{Participant characteristics}

The questionnaire received responses from 247 dancers (225 females and 22 males) from 27 countries, including Australia (86), UK (59), USA (24) and Germany (22). The mean age of females was 20.5 years (SD 8.0) and males 22.5 years (SD 7.1). After data cleaning had been performed: on average, dancers started aged 5.8 (SD 4.1) and those that had transitioned to full-time training did so at 15 years (SD 3.1). Ballet was the main form of dance 
Table 1 Anthropomorphic data of dancers

\begin{tabular}{|c|c|c|c|c|}
\hline Mean (SD) & Height (m) & Weight (kg) & BMI $\left(\mathrm{kg} / \mathrm{m}^{2}\right)$ & $\begin{array}{l}\text { Weight } \\
\text { variability* }^{*}\end{array}$ \\
\hline Females $(n=225)$ & $1.66(0.06)$ & $53.9(7.4)$ & $19.7(2.5)$ & $15 \%(9 \%)$ \\
\hline Males $(n=22)$ & $1.77(0.08)$ & $67.3(8.6)$ & $21.5(2.1)$ & $9 \%(7 \%)$ \\
\hline
\end{tabular}

*Weight variability calculated for current height by dividing the difference between maximum and minimum weight by current weight.

in $85 \%$ of female and $91 \%$ of male dancers. Table 1 shows reported anthropomorphic data. Weight variability of $15 \%$ would be consistent with a dancer weighing $53.9 \mathrm{~kg}$ seeing her adult weight fluctuate between $50 \mathrm{~kg}$ and $58 \mathrm{~kg}$ and her BMI range from 18.2 to $21.2 \mathrm{~kg} / \mathrm{m}^{2}$.

A quarter of dancers had been engaged in on average 10.4 hours (SD 7.1) a week sports training prior to taking up full time dancing. Table 2 shows the current weekly activities of the dancers.

\section{Endocrine status}

Male hormone status was assessed by the number of morning erections, where the average was 4.2. Female hormone history was investigated in greater detail. Primary amenorrhoea: $8 \%$ of females reported that menstruation had never started. For 19\%, periods did not begin until age 15 or later. Of 184 females not taking hormonal contraception, half reported having nine or more cycles per calendar year, while one-third experienced primary $(n=14)$ or secondary amenorrhoea $(n=46)$, with the remaining group having oligomenorrhoea $(n=32)$. Twenty-eight per cent had experienced three or more consecutive months without periods (besides pregnancy or taking hormonal contraception) and a further $26 \%$ stated that this was the current situation. Fifty-eight females had reported to school/company a lack of periods, in $43 \%$ of cases $(n=25)$ the matter was not addressed.

Fifteen per cent of females $(n=34)$ were taking hormonal contraceptives. Of these, half were seeking to prevent pregnancy. Other reasons included reducing bleeding $(35 \%)$, regulating cycles in relation to performances $(32 \%)$, reducing menstrual pain $(14 \%)$, to induce monthly bleeds $(12 \%)$ or medical reasons such as endometriosis $(18 \%)$.

Ninety per cent of females understood that the hormones in the contraceptive pill are not equivalent to the body's hormones. Fifty-seven per cent of male and female participants thought it abnormal for female dancers not to have periods, 23\% thought it normal and $19 \%$ did not know. Seventy-nine per cent of females acknowledged negative consequences from not having periods (apart from not being able to get pregnant), $6 \%$ disagreed and $16 \%$ did not know; while $68 \%$ of males agreed and $32 \%$ did not know.

\section{Illness and injuries}

Most dancers missed relatively few days due to illness or injury, but a small minority had suffered recurrent issues (table 3). Soft-tissue injuries were more prevalent than bone injuries, with a higher incidence of recurrence. Bone fractures were most common in lower limb, pelvis and spine. Among females who had experienced an injury, in $35 \%$ of cases healthcare professionals enquired about periods.

\section{Eating habits}

Twenty-three per cent of females and $5 \%$ of males were vegetarian, while $10 \%$ of male and female dancers were vegan. Fifty-three per cent of females and $36 \%$ of males excluded certain foods from their diets, most commonly meat, followed by carbohydrates. Ninety-eight dancers had been advised by teachers/dancers to exclude foods, most frequently carbohydrates.

Popular sources for nutrition information were the internet $(61 \%)$, professional dietician/nutritionist (32\%), friends/teachers at school/company (29\%), school/company provided access to dietician/nutritionist $(17 \%)$. Eleven per cent did not seek advice on nutrition.

\section{Well-being}

On a rating scale for freshness from 1 (extremely fatigued) to 6 (no fatigue at all), on average females scored 3.7 and males 3.8. For sleep, where 1 (hardly ever get a good night's sleep) to 6 (always), males and females both ranked 4.0 on average. Among those having problems sleeping, common reasons were difficulty falling asleep $(37 \%)$, disrupted sleep $(21 \%)$ and early waking $(18 \%)$.

Ratings for the digestive system, from 1 (continuous problems) to 6 (none), produced an average for females of 4.2 and males 4.5 . $23 \%$ reported no digestive problems,

Table 2 Current activity levels - hours per week

\begin{tabular}{llclll} 
& & & & & \multicolumn{2}{c}{ Conditioning/gym work/ } \\
Mean (SD) & Class & Rehearsal & Performance & supplementary training & Total \\
\hline Females & $15.3(9.3)$ & $9.8(8.6)$ & $1.9(3.0)$ & $5.1(4.2)$ & $29.9(14.2)$ \\
Males & $15.0(9.7)$ & $12.0(10.6)$ & $2.3(3.4)$ & $3.2(2.1)$ & $30.4(13.8)$ \\
\hline
\end{tabular}


Table 3 IIIness and injuries in dancers

\begin{tabular}{lllllll}
\hline $\begin{array}{l}\text { Mean and } \\
\text { range }\end{array}$ & $\begin{array}{l}\text { Days off dancing } \\
\text { due to illness in last } \\
\text { year }\end{array}$ & $\begin{array}{l}\text { Days off dancing } \\
\text { due to injury in last } \\
\text { year }\end{array}$ & $\begin{array}{l}\text { Soft-tissue } \\
\text { injuries from } \\
\text { dancing }\end{array}$ & $\begin{array}{l}\text { Recurrent } \\
\text { soft-tissue } \\
\text { injuries }\end{array}$ & $\begin{array}{l}\text { Bone } \\
\text { injuries from } \\
\text { dancing }\end{array}$ & $\begin{array}{l}\text { Recurrent } \\
\text { bone } \\
\text { injuries }\end{array}$ \\
\hline Females & $6.3(0$ to 180$)$ & $13(0$ to 200$)$ & $1.5(0$ to 14$)$ & $1.0(0$ to 7$)$ & $0.6(0$ to 6$)$ & $0.4(0$ to 7$)$ \\
Males & $3.5(0$ to 20$)$ & $10(0$ to 80$)$ & $2.1(0$ to 10$)$ & $1.5(0$ to 5$)$ & $0.5(0$ to 2$)$ & $0.3(0$ to 2$)$ \\
\hline
\end{tabular}

while $35 \%$ had bloating, 23\% suffered discomfort and $12 \%$ constipation.

\section{Psychological factors}

Attitudes to training

Seventy-one per cent of respondents reported feeling worried about missing a session, with common reasons being missing out on learning choreography and potential roles, loss of technique, guilt or absence noticed by teachers.

\section{Attitudes to weight and eating}

Forty-four per cent of females and 32\% of males reported being told to lose weight at some point in their training/ professional career, mainly by teaching staff/directors. Eighty-three per cent of dancers were influenced to some extent by social media in trying to lose weight, with $30 \%$ of females and $14 \%$ of males saying this was a constant influence.

Dancers reported weighing themselves on average 1.8 times a week. Forty-two per cent did not track their weight, while fewer than $10 \%$ weighed themselves more than three times a week. Using a scale of 1 (no effect) to 6 (very important), female dancers felt that their ability to control what they eat (4.6) and what they weigh (4.1) affected their self-esteem more than males, 4.0 and 3.1, respectively.

Dancers generally considered their best dance weight to be lower than their current weight: on average, females would prefer to lose $1.8 \mathrm{~kg}$ and males $1.3 \mathrm{~kg}$. $71 \%$ of females and $43 \%$ of males agreed that a leading role would favour someone of lower weight for height.

The boxplots in figure 1 show six statistically significant interrelationships among the psychological factors and between psychological factors and both physical and physiological function of the female dancers. The top panel shows that female dancers who were worried/ anxious about missing training also scored more highly in their responses to two other psychological factors: the desire to control diet and to control weight. The central panel illustrates that dancers, whose minimum BMI was low (below the average BMI min), also scored more highly on these psychological control factors. The final panel demonstrates a similar relationship between irregular menstrual function and psychological factors.

\section{Eating disorders}

Eating disorders had been diagnosed in $15 \%$ of females and $14 \%$ of males: these included anorexia nervosa
$(64 \%)$, bulimia (22\%). Disordered eating: orthorexia $(8 \%)$.

\section{Awareness}

Twenty-nine per cent had heard of RED-S and 37\% LEA. Thirty per cent had come across the female athlete triad. Ninety per cent were aware of terms disordered eating, $46 \%$ orthorexia.
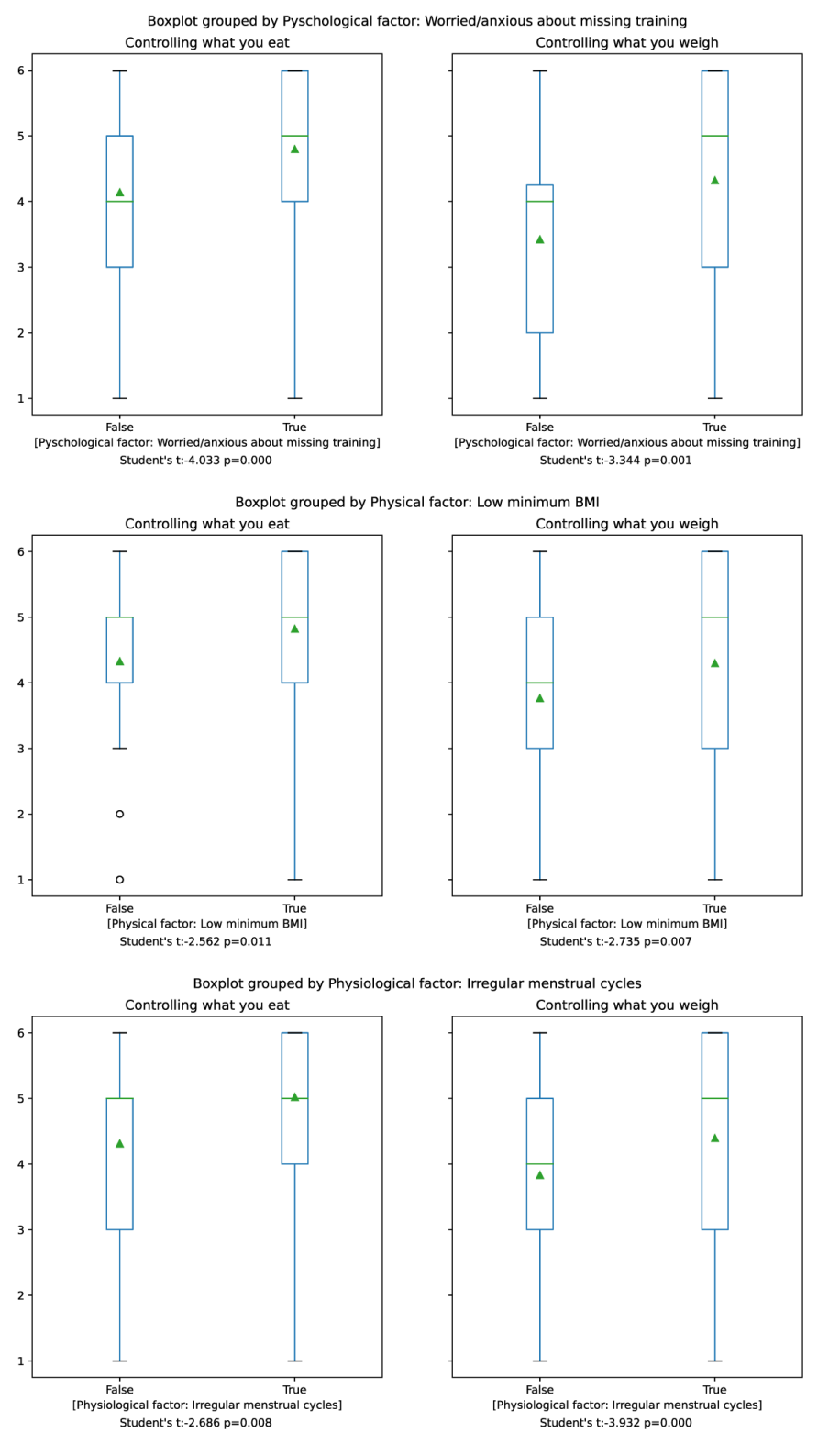

Figure 1 Inter-relationships of psychological, physical and physiological factors. BMI, body mass index. 


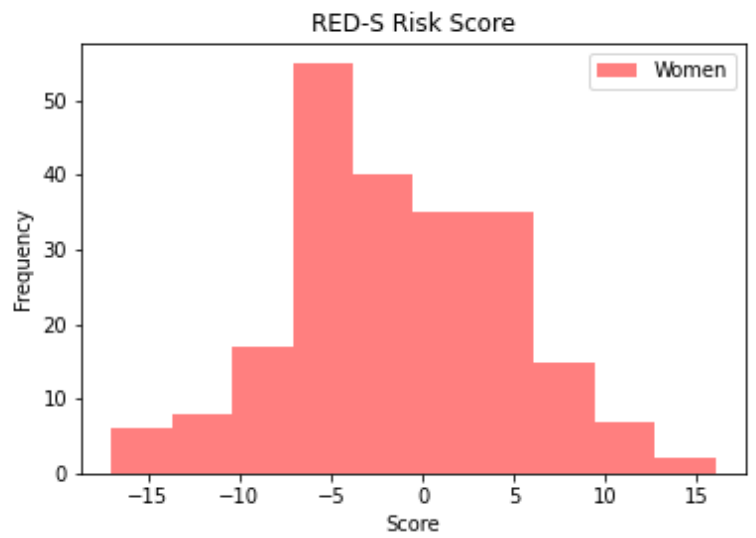

Figure 2 RED-S risk score for female dancers. RED-S, relative energy deficiency in sport.

\section{RED-S risk scores}

RED-S risk scores ranged from -17 to +16 , with negative scores indicating LEA and therefore higher risk of RED-S. The average score for females (figure 2) was -1.4 (SD 6.1) and +2.3 (SD 6.0) for males (figure 3). Negative scores were seen in $57 \%$ female dancers and $29 \%$ male dancers. Females with the modal score of -5 were characterised as having relatively low BMI (19.0) and BMI min (17.3), often had hormone issues (late menarche, irregular or disrupted cycles), over a week off due to injury and strong desires to control diet (5.2 out of 6 ) and weight (4.6 out of 6$)$.

\section{DISCUSSION}

A Dance-Specific Questionnaire (DEAQ) investigating physical, physiological and psychological indicators and correlates showed that dancers are a specific group of high-level artistic performers displaying indicators of LEA and at risk of RED-S.

\section{RED-S risk score from DEAQ}

The DEAQ was derived from a questionnaire-based approach similar to that applied to sports. Negative RED-S risk scores, calculated from the DEAQ, indicated LEA in

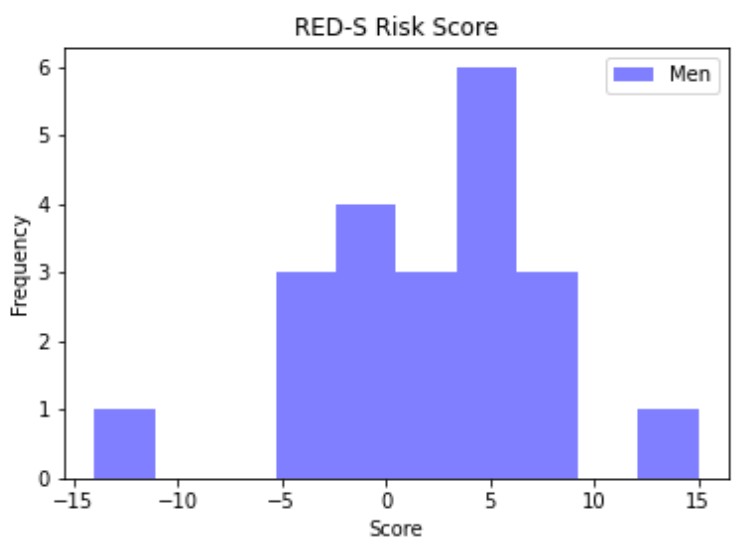

Figure 3 RED-S risk score for male dancers. RED-S, relative energy deficiency in sport.
$57 \%$ of female and $29 \%$ of male dancers, suggesting that these dancers are at risk of developing the clinical consequences of RED-S, in common with athletes in certain sports. ${ }^{56}$ Yet only $29 \%$ of dancers had heard of RED-S. The DEAQ addresses the cultural gap between dance and sport by presenting an established screening questionnaire in a dance friendly format.

While there are fewer RED-S studies in male athletes, ${ }^{6}$ the identification of males dancers at risk is consistent with findings from a self-report survey of male athletes ${ }^{15}$ and a study of male cyclists where results from a questionnaire were linked with quantified clinical consequences of RED-S. ${ }^{12}$ Nevertheless, the average risk score for male dancers was not as marked as in females, although fewer males responded to the questionnaire than females. Males perform a different repertoire from females, reflected in a lower percentage of males being advised to lose weight and fewer seeing low weight as a factor in being cast. However, in common with females, the male dancers expressed a desire to be lighter and linked controlling what they ate to self-esteem.

\section{Physical aspects of LEA in dancers}

Ballet, the main dance form in this study, is practised worldwide and requires a slim physique to meet aesthetic, technical and repertoire demands. Ballet also forms part of the early training of dancers who go on to practise other genres. Literature review indicates that for female dancers of all skill levels, disordered eating, menstrual disruption and poor bone health are significant health issues. ${ }^{16}$ Early training specialisation, combined with a high training load, found in this study, is characteristic of dance. ${ }^{2}$ Intensive training during the teenage years increases the already considerable energy demands of physical development. This situation is recognised as an early risk factor for developing female athlete triad. ${ }^{3}{ }^{17}$ Our study found BMI at the lower end of range (average for female dancers 19.7) and large variation in adult weight ( $15 \%$ for female dancers). In a study of retired female dancers, low BMI and duration of amenorrhoea during a dance career were found to be independent variables for low BMD in the long term. ${ }^{4}$

\section{Physiological indicators of LEA in dancers}

Endocrine function: Menstrual status in females and testosterone levels in males are sensitive, objective indicators of LEA, linked to the clinical outcome of impaired bone health and stress fracture of RED-S. ${ }^{18}$ Menstrual disruption, in particular functional hypothalamic amenorrhoea due to LEA, is characteristic of the clinical risk assessment of RED-S. ${ }^{13}$ The high incidence of menstrual disruption among dancers in this study, is far in excess of general population ${ }^{19}$ : primary amenorrhoea $8 \%$ vs less than $0.01 \%$ and combined primary and secondary amenorrhoea $33 \%$ vs $4 \%$. A history of amenorrhoea was reported $28 \%$ in dancers. Oligomenorrhoea associated with increase in training loads was reported in $17 \%$ of dancers. Overall, half of the female dancers 
reported disrupted menstrual function. Extensive literature demonstrates adverse health outcomes of the hypo-oestrogen state in terms of impaired bone, cardiovascular and neuromuscular function. ${ }^{20-22}$ Although $79 \%$ female dancers recognised that lack of menstrual cycles could have adverse consequences; $23 \%$ considered this 'normal' for dancers. This erroneous view might be perpetuated by a failure of staff to address amenorrhoea $(43 \%)$ or enquire about menstruation on presentation of injury (35\%), despite amenorrhoeic status being a well-documented risk factor for both soft tissue and bone stress injuries.[18]. ${ }^{18}$

Gastrointestinal function: Disrupted gastrointestinal function is a well documented, validated indicator of LEA. ${ }^{9}$ Seventy-seven per cent dancers reported such digestive issues indicative of LEA. Misinterpretation of these symptoms can prompt further restrictive practices: half of female dancers and one-third of male dancers were excluding food groups. Furthermore, a third of dancers reported food intolerances, although very few had actually been formally tested.

Injuries: Incidence of injury was lower than might be expected, in view of the high percentage of dancers assessed as being in LEA, compared with high rate of stress fracture reported in male and female runners in LEA. ${ }^{18}$ However, the consequences of LEA occurring during peak bone mass accumulation manifest with an increased incidence of stress fractures during mid-20s. ${ }^{23}$ Furthermore, dancers in this study were not preselected by attending an sports injury clinic in a questionnairebased study of female athletes. ${ }^{10}$

\section{Psychological aspects as correlates for LEA in dancers}

Psychological factors in athletes can both contribute to the cause and be the consequence of LEA. ${ }^{5}$ This study found a significant interplay between the psychological cluster of control of weight, eating and exercise dependence. Both male and female dancers indicated that controlling what they ate and what they weighed were important factors linked with self-esteem. Psychological drivers of competitiveness, perfectionism and self-control can render athletes susceptible to disordered eating behaviours. ${ }^{24}$ Development of attitudes regarding 'ideal' body type/weight and teammate modelling of eating behaviours can trigger disordered eating in junior athletes and pre-professional dancers. ${ }^{25}{ }^{26}$ Vocational training and dance performance involve living away from home, often abroad, where dancers may use dance peers and social media as comparators. Eighty-three per cent of dancers cited social media as influential in feeling that weight loss was desirable.

Seventy-one per cent of dancers in this study reported feeling anxious about missing class. Exercise dependence is reported as a reliable indicator of eating psychopathology tendencies in female athletes ${ }^{27}$ and biochemical indicators of RED-S in male athletes. ${ }^{11}$

From this study, a statistically significant relationship was found between psychological factors and physical outcome of BMI min. The perceived performance advantage of weight loss can be a driver of disordered eating in aesthetic sports and dance. ${ }^{28}{ }^{29}$ In our study, $73 \%$ of female dancers stated that being of low body weight would improve chances of being cast in significant roles. Forty-four per cent of female dancers and 33\% of males reported being advised, at some point, to lose weight. Most commonly, dancers had been encouraged to exclude carbohydrates, contrary to research showing that low carbohydrate diets limit physical performance at high intensities. ${ }^{30}$

Our study found a significant relationship between the psychological factors of control and physiological outcome of menstrual function. Dancers expressed dissatisfaction with their current weight, wishing to be lighter, in keeping with the drive for thinness being an indicator of LEA, with increased menstrual disruption, ${ }^{31}$ reduced triiodothyronine and resting metabolic rate (RMR) ${ }^{32}$ Reduced RMR in male and female dancers is an indicator of LEA. ${ }^{33}$

'Thinness-related learning' for dancers, who already have perfectionist traits, is cited as increasing the risk for eating disorders. ${ }^{34}$ This study revealed a lifetime incidence of an eating disorder of $15 \%$ for female and $14 \%$ for male dancers, primarily anorexia nervosa. These findings are comparable to those previously reported in dancers and athletes and being higher than the non-athletic population. ${ }^{35}{ }^{36}$ Exclusion of food groups by choice was reported by $50 \%$ female and $33 \%$ of male dancers.

A detrimental interplay of psychological factors for LEA can be perpetuated by the nature of dance training and performance, where selection strongly favours certain physical and psychological characteristics.

\section{Limitations and further work}

The aim of this study was to obtain a global picture of dance health and specifically trial a DEAQ. While there are different schools of ballet and companies vary in their approaches, dance training follows a very similar pattern worldwide. Nevertheless, this study was observational and cross-sectional, with potential for self-selection bias, particularly in case of male dancers, which could account for polarised scores.

Further current longitudinal research is investigating male and female dancers in the same company. This study includes use of DEAQ to validate in its entirety, with monitoring of biometrics, including training load, wellbeing, injury, menstrual tracking, hormone profiling and dance performance. The outcomes of educational intervention directed at behavioural change will be studied.

\section{CONCLUSIONS}

The DEAQ indicates that dancers can display indicators of LEA, linked to high training loads, psychological drivers and external influences from initiation of dance training at an early age. The DEAQ could potentially be a practical, objective health-screening tool and identify dancers in LEA, at risk of developing RED-S. Further 
prospective work is underway to combine the DEAQ with longitudinal monitoring clinical biometric measures and dance performance.

\section{Twitter Nicola Keay @nickyKfitness}

Acknowledgements Thank you to all the dancers for their interest and participation in this study. Thanks to AusDancers Overseas for input. Thanks to One Dance UK. Thanks to teaching and research staff at Sport Science Department at Durham University.

Collaborators AusDancers Overseas, Professor Karen Hind (Durham University).

Contributors NK and AO: conceptualisation of project, development of study design, involvement of dancers, drafting and revision manuscript. GF: advanced statistical analysis drafting and revision of manuscript.

Competing interests None declared.

Patient consent for publication Not required.

Ethics approval The study was approved by the Durham University ethics committee 23/4/19 Ref SPORT-2019-03-15T17_50_49.

Provenance and peer review Not commissioned; externally peer reviewed.

Data availability statement Data are available on reasonable request.

Open access This is an open access article distributed in accordance with the Creative Commons Attribution Non Commercial (CC BY-NC 4.0) license, which permits others to distribute, remix, adapt, build upon this work non-commercially, and license their derivative works on different terms, provided the original work is properly cited, appropriate credit is given, any changes made indicated, and the use is non-commercial. See: http://creativecommons.org/licenses/by-nc/4.0/.

ORCID iD

Nicola Keay http://orcid.org/0000-0001-6663-7010

\section{REFERENCES}

1 Warren MP. The effects of exercise on pubertal progression and reproductive function in girls. $J$ Clin Endocrinol Metab 1980;51:1150-7.

2 Keay N. Dancing through adolescence. Br J Sports Med 1998;32:196-7.

3 Keay N. The modifiable factors affecting bone mineral accumulation in girls: the paradoxical effect of exercise on bone. Nutr Bull 2000;25:219-22.

4 Keay N, Fogelman I, Blake G. Bone mineral density in professional female dancers. Br J Sports Med 1997;31:143-7.

5 Mountjoy M, Sundgot-Borgen J, Burke L, et al. The IOC consensus statement: beyond the Female Athlete Triad--Relative Energy Deficiency in Sport (RED-S). Br J Sports Med 2014;48:491-7.

6 Mountjoy M, Sundgot-Borgen JK, Burke LM, et al. IOC consensus statement on relative energy deficiency in sport (RED-S): 2018 update. Br J Sports Med 2018;52:687-97.

7 Burke LM, Lundy B, Fahrenholtz IL, et al. Pitfalls of conducting and interpreting estimates of energy availability in free-living athletes. Int $J$ Sport Nutr Exerc Metab 2018;28:350-63.

8 Wells KR, Jeacocke NA, Appaneal R, et al. The Australian Institute of sport (AIS) and national eating disorders collaboration (NEDC) position statement on disordered eating in high performance sport. Br J Sports Med 2020;54:1247-58.

9 Melin A, Tornberg AB, Skouby S, et al. The leaf questionnaire: a screening tool for the identification of female athletes at risk for the female athlete triad. Br J Sports Med 2014:48:540-5.

10 Ackerman KE, Holtzman B, Cooper KM, et al. Low energy availability surrogates correlate with health and performance consequences of relative energy deficiency in sport. Br J Sports Med 2019;53:628-33.

11 Torstveit MK, Fahrenholtz IL, Lichtenstein MB, et al. Exercise dependence, eating disorder symptoms and biomarkers of relative energy deficiency in sports (RED-S) among male endurance athletes. BMJ Open Sport Exerc Med 2019;5:e000439.

12 Keay N, Francis G, Hind K. Low energy availability assessed by a sport-specific questionnaire and clinical interview indicative of bone health, endocrine profile and cycling performance in competitive male cyclists. BMJ Open Sport Exerc Med 2018;4:e000424.
13 Mountjoy M, Sundgot-Borgen J, Burke L, et al. RED-S cat. relative energy deficiency in sport (RED-S) clinical assessment tool (cat). $\mathrm{Br}$ J Sports Med 2015;49:421-3.

14 Morley JE, Charlton E, Patrick P, et al. Validation of a screening questionnaire for androgen deficiency in aging males. Metabolism 2000;49:1239-42.

15 Logue DM, Madigan SM, Melin A, et al. Self-Reported reproductive health of athletic and recreationally active males in Ireland: potential health effects interfering with performance. Eur J Sport Sci 2020:1-10.

16 Hincapié CA, Cassidy JD. Disordered eating, menstrual disturbances, and low bone mineral density in dancers: a systematic review. Arch Phys Med Rehabil 2010;91:1777-89.

17 Joy E, De Souza MJ, Nattiv A, et al. 2014 female athlete triad coalition consensus statement on treatment and return to play of the female athlete triad. Curr Sports Med Rep 2014;13:1-32.

18 Heikura IA, Uusitalo ALT, Stellingwerff T, et al. Low energy availability is difficult to assess but outcomes have large impact on bone injury rates in elite distance athletes. Int J Sport Nutr Exerc Metab 2018;28:403-11.

19 Solnik M. Assessment of primary amenorrhoea. BMJ Best Pract, 2014. Available: https://bestpractice.bmj.com/topics/en-gb/1101 [Accessed 10 Jan 2020].

20 Mallinson RJ, De Souza MJ. Current perspectives on the etiology and manifestation of the "silent" component of the Female Athlete Triad. Int J Womens Health 2014:6:451-67.

21 O'Donnell E, De Souza MJ. The cardiovascular effects of chronic hypoestrogenism in amenorrhoeic athletes: a critical review. Sports Med 2004;34:601-27.

22 Tornberg Åsa B, Melin A, Koivula FM, et al. Reduced neuromuscular performance in amenorrheic elite endurance athletes. Med Sci Sports Exerc 2017;49:2478-85.

23 Ackerman KE, Cano Sokoloff N, DE Nardo Maffazioli G, et al. Fractures in relation to menstrual status and bone parameters in young athletes. Med Sci Sports Exerc 2015;47:1577-86.

24 Stirling A, Kerr G. Perceived vulnerabilities of female athletes to the development of disordered eating behaviours. Eur J Sport Sci 2012;12:262-73.

25 Melin AK, Heikura IA, Tenforde A, et al. Energy availability in athletics: health, performance, and physique. Int J Sport Nutr Exerc Metab 2019;29:152-64.

26 Wyon MA, Hutchings KM, Wells A, et al. Body mass index, nutritional knowledge, and eating behaviors in elite student and professional ballet dancers. Clin J Sport Med 2014;24:390-6.

27 Plateau CR, Arcelus J, Meyer C. Detecting eating psychopathology in female athletes by asking about exercise: use of the compulsive exercise test. Eur Eat Disord Rev 2017;25:618-24.

28 Krentz EM, Warschburger P. A longitudinal investigation of sportsrelated risk factors for disordered eating in aesthetic sports. Scand $J$ Med Sci Sports 2013;23:303-10.

29 Gearhart MG, Sugimoto D, Meehan WP, et al. Body satisfaction, performance perception, and weight loss behavior in young female dancers. Med Probl Perform Art 2018;33:225-30.

30 Burke LM, Ross ML, Garvican-Lewis LA, et al. Low carbohydrate, high fat diet impairs exercise economy and negates the performance benefit from intensified training in elite race walkers. $J$ Physiol 2017;595:2785-807

31 Gibbs JC, Williams NI, Scheid JL, et al. The association of a high drive for thinness with energy deficiency and severe menstrual disturbances: confirmation in a large population of exercising women. Int J Sport Nutr Exerc Metab 2011;21:280-90.

32 De Souza MJ, Hontscharuk R, Olmsted M, et al. Drive for thinness score is a proxy indicator of energy deficiency in exercising women. Appetite 2007;48:359-67.

33 Staal S, Sjödin A, Fahrenholtz I, et al. Low RMR ratio $_{\text {a }}$ as a Surrogate Marker for Energy Deficiency, the Choice of Predictive Equation Vital for Correctly Identifying Male and Female Ballet Dancers at Risk. Int $J$ Sport Nutr Exerc Metab 2018;28:412-8.

34 Penniment KJ, Egan SJ. Perfectionism and learning experiences in dance class as risk factors for eating disorders in dancers. Eur Eat Disord Rev 2012;20:13-22.

35 Arcelus J, Witcomb GL, Mitchell A. Prevalence of eating disorders amongst dancers: a systemic review and meta-analysis. Eur Eat Disord Rev 2014:22:92-101.

36 Joy E, Kussman A, Nattiv A. 2016 update on eating disorders in athletes: a comprehensive narrative review with a focus on clinical assessment and management. Br J Sports Med 2016;50:154-62. 